\title{
Towards Development and Validation of a Simplified Infiltration Model for Commercial Buildings
}

\author{
Adam Douglas Wills, Iain Macdonald, Justin Berquist, Carsen Banister, \\ Michal Bartko, and Mark Vuotari \\ National Research Council Canada, Ottawa, Canada
}

\begin{abstract}
As building envelopes continue to become more thermally insulated, the impact of exfiltration/infiltration on space heating demand will become increasingly significant. Heat transfer through opaque and transparent envelope components is well-understood and characterized in building performance simulation (BPS); however, simple constant flow assumptions are often used for modelling air infiltration which can result in substantial inaccuracies in estimated performance. A detailed building thermal and air flow network model was developed as a case study to examine the sensitivity of envelope leakage site distribution to annual space heating energy. Additionally the model was used to determine if this sensitivity diminishes as a building is pressurized. Results of the case study indicate that distribution of leakage area varies annual energy estimates and average infiltration by $\pm 3 \%$ and $\pm 10 \%$, respectively, when unpressurized. Pressurization was found to significantly increase sensitivity of annual space heating demand to leakage distribution.
\end{abstract}

\section{Introduction and background}

The National Energy Code of Canada for Buildings (NECB) (CCBFC, 2015) provides two principle pathways for compliance: following prescriptive requirements described in the code, or following a performance compliance path. The performance compliance path requires a designer to calculate the annual total energy consumption of a reference building defined by the code, and a proposed building. The proposed design must be shown to not exceed the annual energy consumption of the reference. There has also been recent consideration of using energy intensity targets to demonstrate compliance of proposed buildings. This method of compliance has already been adopted in the Energy Step Code of the Canadian province of British Columbia (Province of British Columbia, 2017).

It has been suggested by Canadian industry and authorities having jurisdiction that most designers opt for the performance compliance path for commercial buildings, and is typically demonstrated us- ing building performance simulation (BPS) (Girgis, 2012). Thermal energy transfer by conduction through building envelope components is generally well understood, and accurately characterized in BPS tools (Judkoff and Neymark, 1995). However, some of the other energy transfer processes in buildings are less understood and difficult to characterize in energy models. One such process is building air leakage. A simplified approach is often used due to a lack of information on leakage site size and location (Deru et al., 2011).

In the NECB, both the reference and proposed building must assume a constant infiltration rate of 0.25 $\mathrm{L} /\left(\mathrm{s} \cdot \mathrm{m}^{2}\right)$ of gross above-grade wall and roof area. This simplification may have been acceptable in the past, but newer construction in Canada is trending toward envelopes with higher thermal resistance; consequently, the sensitivity of energy performance calculations to air leakage modelling is also increasing. Additionally industry is interested in receiving credits in the building code for envelope air sealing measures. Therefore, there is greater importance to understand and accurately model envelope air leakage. There are several approaches available for building air leakage modelling, however, it is unclear which approaches and assumptions are best suited for determining building code compliance.

\section{Building air flow modelling techniques}

Clarke (2001) previously summarized building air movement modelling techniques. They are, from simplest to most complex:

1. Scheduled air flow,

2. Empirical models,

3. Air flow networks (AFN),

4. Computational fluid dynamics (CFD).

Scheduled air flow uses prescribed constant or scheduled flow rates between zones, and between zones and the ambient environment. This is a computationally and conceptually simple approach, but "[relies] on guessed or estimated values of airflow" (Djunaedy et al., 2003). This is currently the method used in the 2017 NECB. 
Empirical infiltration models include methods which regress data from building leakage tests. Two commonly used empirical techniques for residential buildings are the Lawrence Berkeley Laboratory (LBL) Infiltration model (Sherman and Grimsrud, 1980b), and the Alberta Infiltration (AIM-2) model (Walker and Wilson, 1990). Both of these approaches use a power law formulation to model whole-building commercial infiltration as a function of the envelope pressure differential. Infiltration models in EnergyPlus, summarized by Gowri et al. (2009), use different formulations for empirical modelling of building infiltration dependent on indoor-outdoor temperature difference and wind speed. All empirical approaches require knowledge of envelope leakage at a minimum of one envelope pressure difference. This data may be obtained from building fan depressurization tests, however, for high-rise and large commercial buildings, fan depressurization tests are often impractical. These tests require all occupants to vacate the building and several fans are needed to reach desired pressure differentials.

AFNs are a more fundamental approach to building air movement modelling. Rather than relying on empirical data, the basis of the AFNs is to abstract buildings into a network of nodes interconnected by flow inducers, such as fans, and flow resistors, such as ducts (Hensen, 1991). Flow between nodes is characterized using steady-state Bernoulli equations. Climate data and wind-induced pressure coefficients provide known pressure boundary conditions to the network, and the interior node pressures and subsequent mass flow between the nodes is solved iteratively for each simulation timestep. Shaw and Tamura (1977) previously modelled tall commercial buildings using an AFN and pressure data collected from wind tunnel experiments. Leakage area for each building zone was lumped to a single leakage site. Ng et al. (2013) compared scheduled flow models to detailed AFN models and stated that "assuming constant infiltration airflow rates in energy simulation, no matter the value, cannot capture the important effects of weather on infiltration."

A benefit of the AFN approach is that it does not require empirical data from buildings. Therefore, during the initial and late design stages an AFN can be used to estimate building air flow. The challenge of this approach is that building leakage sites are not always apparent to a simulation practitioner, and characterizing the flow characteristics of leakage sites is non-trivial.

The basic principle of CFD is to discretize a building, or a section of a building into finite (small) regions (Clarke, 2001). Specialized solvers are then used to determine air movement between the finite regions. This approach is well-adapted to studies which analyze air movement within a space to characterize thermal comfort or air quality. However, for whole- building energy analyses CFD is often too computationally expensive and requires a high detail for inputs.

\section{Objectives}

To better characterize infiltration in new construction, and provide credit to builders incorporating airtight designs, more detailed infiltration modelling approaches are needed for code-compliance demonstration. Empirical models and AFNs are potential candidates, but the detailed inputs required for these methods create challenges for building energy model practitioners, especially pre-construction. One major challenge is identifying how total envelope leakage is distributed. Walker and Wilson (1990) found that for small residential buildings the location of envelope leakage sites has a significant impact on infiltration estimates.

The sensitivity for commercial buildings is less understood. Compared to residential, commercial HVAC systems often produce net-positive or net-negative pressures for moisture and indoor air quality control (Lstiburek and Carmody, 1994). The objective of this paper is to examine how the sensitivity of annual energy performance to envelope leakage distribution varies with pressurization for a low-rise commercial building. The hypothesis is that as the building is pressurized there is a reduced sensitivity to leakage location.

\section{Methodology}

To meet the objectives of the paper, a case study building was used and modelled in the detailed BPS tool ESP-r (Clarke, 2019). The following provides a description of the building and the modelling methodology.

\section{Case Study Building}

The building considered for the case study is pictured in Figure 1. This building is the Indoor Air Research Laboratory (IARL) located at the National Research Council of Canada campus in Ottawa, Ontario. The IARL is a two storey building which includes a full basement, and garage. The facility is also equipped with 31 envelope ports, shown as the metal discs in Figure 1. Each port contains a motorized damper which is controlled through the facility's building automation system (BAS). The purpose of these ports is to vary both the total envelope leakage area, as well as leakage location. 


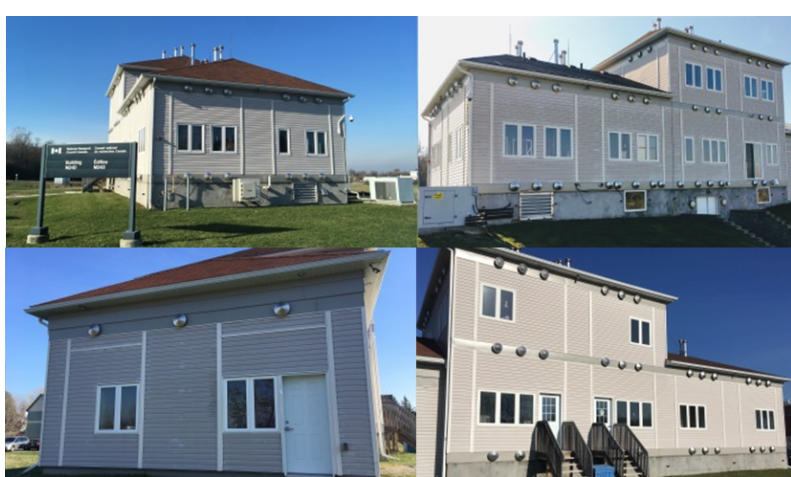

Figure 1: IARL test facility.

During spring 2018, a building depressurization test of the IARL was conducted per Standard CAN/CGSB-149.10-M86 (CGSB, 1986). For this test all envelope ports were set to the closed position. This test was used to determine the CGSB standard equivalent leakage area (ELA), defined in ASHRAE (2009), and the effective leakage area $\left(A_{L}\right)$, defined in ASTM (2010). A summary of the test results are provided in Table 1. Note that the CGSB standard determines leakage area at $\Delta \mathrm{P}=10 \mathrm{~Pa}$, whereas in the U.S. leakage area is typically determined at $\Delta \mathrm{P}=4 \mathrm{~Pa}$.

Table 1: IARL blower door test results.

\begin{tabular}{lc}
\hline \hline Test Results at $\mathbf{5 0} \mathbf{P a}$ & \\
\hline \hline Air flow $\left[\mathrm{m}^{3} / \mathrm{s}\right]$ & $0.912 \pm 1.7 \%$ \\
ACH50 [-] & 2.30 \\
\hline \hline Leakage Areas & \\
\hline \hline ELA @ $10 \mathrm{~Pa}\left[\mathrm{~m}^{2}\right]$ & $0.172 \pm 5.0 \%$ \\
\hline$A_{L} @ 10 \mathrm{~Pa}\left[\mathrm{~m}^{2}\right]$ & $0.105 \pm 5.0 \%$ \\
$A_{L} @ 4 \mathrm{~Pa}\left[\mathrm{~m}^{2}\right]$ & $0.108 \pm 8.2 \%$ \\
\hline \hline
\end{tabular}

The facility utilizes a BAS to control the facility. The BAS allows for the control of a dedicated air handling unit (AHU) and was programmed with the capability to maintain desired positive building pressures. The BAS can also control motorized dampers located on the supply and return ducts for each room in the facility. This allows for complete control of the airflow to and from the rooms.

\section{Simulation Tool and Methodology}

ESP-r is an open-source tool which has undergone extensive validation since its inception in 1977 (Strachan et al., 2008). ESP-r is also one of the benchmarking software included in ASHRAE Standard 140 (ASHRAE, 2011). The core solver of ESP-r uses a finite-difference approach to calculate thermal energy transfer through building materials and between interior spaces. ESP-r also contains several specialized solvers for modelling other physical building processes, including air flow networks, CFD, and building HVAC and energy systems.

\section{Model Description}

Architectural drawings of the IARL were used to construct a building envelope model in ESP-r, shown in Figure 2. The IARL was discretized into seven thermal zones: three attic zones, garage, basement, first and second floor. Since accurate modelling of solar gain distribution in the interior space was not an objective of the research, glazing and door surfaces on each wall face were lumped together to increase computational efficiency.

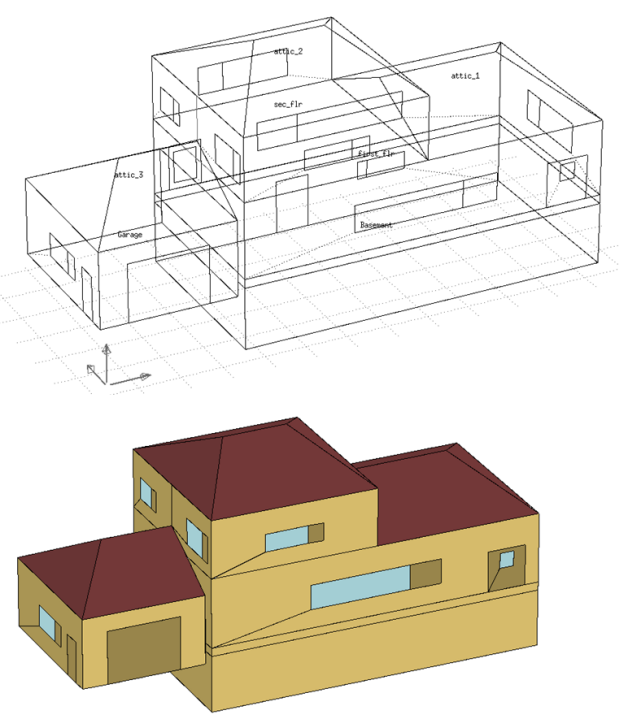

Figure 2: Wire frame and rendered ESP-r model.

Principal building model characteristics are provided in Table 2. The gross wall areas do not include the garage, or the partition walls between the garage and main spaces since these surfaces are not in direct contact with the exterior. Building height is taken from the ground to the ceiling of the second floor. Main walls and ceilings below attics were modelled as having an effective thermal resistance of 4.13 and 7.20 $\mathrm{m}^{2} \cdot \mathrm{K} / \mathrm{W}$, respectively.

Table 2: IARL geometric characteristics.

\begin{tabular}{ll}
\hline \hline Parameter & Value \\
\hline \hline Heated floor area $\left[\mathrm{m}^{2}\right]$ & 408 \\
Heated volume $\left[\mathrm{m}^{3}\right]$ & 1424 \\
Gross exposed above-grade wall area & 353 \\
{$\left[\mathrm{~m}^{2}\right]$} & \\
Gross below-grade wall area $\left[\mathrm{m}^{2}\right]$ & 111 \\
Total glazing area $\left[\mathrm{m}^{2}\right]$ & 46.4 \\
Building height above-grade $[\mathrm{m}]$ & 8 \\
\hline \hline
\end{tabular}

Model boundary conditions were provided from the 2016 version of the Canadian Weather year for Energy Calculation (CWEC) file (ECCC, 2018) for Ottawa, Ontario. Heating was modelled as directly supplied to the air of the basement, first, and second floor zones with infinite heating capacity. The heating setpoint 
temperature was a prescribed constant of $22{ }^{\circ} \mathrm{C}$. No cooling capacity was provided to the spaces. No internal gains were modelled.

\section{Modelling Air Flow}

The AFN developed for the IARL model is illustrated in Figure 3. Internal air flow nodes were defined for each of the conditioned thermal zones. The temperature of each node is determined for each timestep by the ESP-r thermal solver and nodal pressures are determined iteratively each timestep by the flow solver.

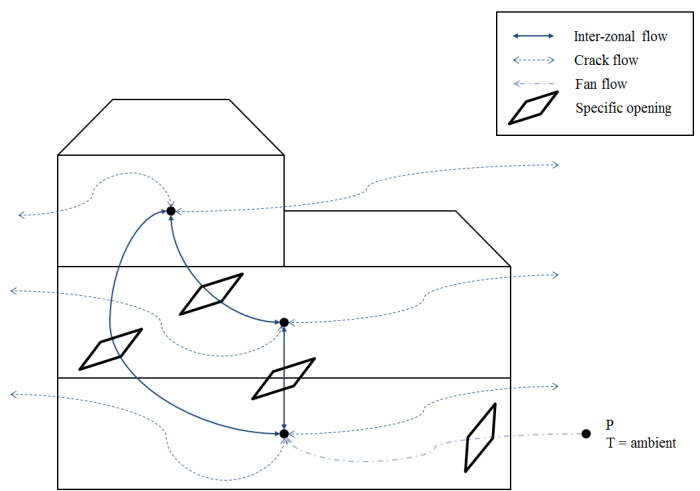

Figure 3: Simplified IARL AFN schematic.

Air movement between interior and exterior was modelled using "crack" components. Details of these components may be found in Hensen (1991). For the first and second floor zones, crack components were defined at the floor, mid-height of the wall, and ceiling of the zone for each façade facing. The basement zone was modelled with crack components along the ceiling only. Each component was modelled as $1 \mathrm{~mm}$ in height with variable length ${ }^{1}$ and is connected to an associated interior node and individual exterior winddriven boundary node.

Pressure at the boundary node is calculated each simulation timestep as a function of wind speed and direction, and pressure coefficients. These coefficients may be determined experimentally or from CFD. Liddament (1986) developed a set of coefficients for basic building plan shapes up to three storeys tall that may be used as approximations, and were used for this study. 1:2 and 1:1 exposed ratio pressure coefficients were used for the first floor and basement and the second floor, respectively.

The locations of the crack components are illustrated by the coloured rectangles in Figure 4. For this study, the crack components were clustered into five groups, illustrated by the matching colours and labels in Figure 4. Each group is allocated a portion of the total envelope leakage area as inputs. Within each group, the allocated area is then distributed to the cracks

\footnotetext{
${ }^{1}$ The resistance to flow through the crack varies linearly with length, as shown in Hensen (1991).
}

in proportion to the length/width ratio of the zone perimeter. Thus, the sensitivity to the facing direction of the leakage area is not considered in this study, only the vertical distribution of leakage area.

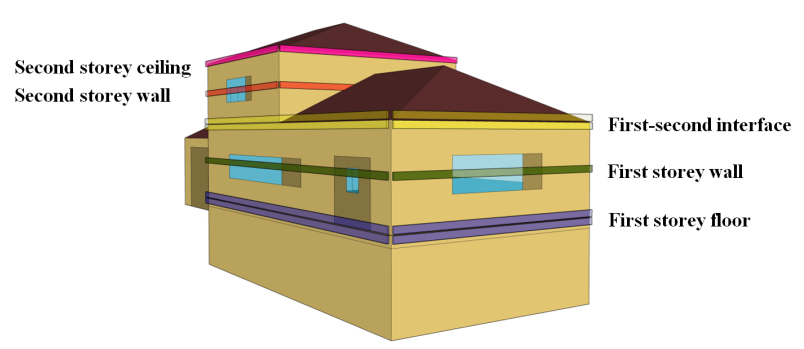

Figure 4: Relative elevations of the crack groups.

The first storey floor and first-second interface groups are special cases where the cracks are located between thermal zones. For these groups, two cracks are modelled for each façade; one for each adjacent thermal zone. The area specified for the cracks on that façade are divided evenly between the two crack components. The relative elevations of the groups are provided in Table 3 .

Table 3: Relative elevations of the crack component groups.

\begin{tabular}{ll}
\hline \hline Group & Elevation $[\mathbf{m}]$ \\
\hline \hline First storey floor & 0 \\
First storey wall & 2.1 \\
First-second interface & 3.7 \\
Second storey wall & 5.5 \\
Second storey ceiling & 6.8 \\
\hline \hline
\end{tabular}

\section{Simulation Plan}

Four building pressurization scenarios were considered in this study: none, 5, 10, and 15 Pa. Pressurization was characterized as the pressure difference between indoor and ambient static pressure. For each operation scenario, a Monte Carlo approach was used to examine sensitivity. A simple random sampling technique was used to generate 500 samples. Each sample was created by stochastically distributing total envelope leakage area to the five crack groups listed in Table 3 , and simulated at a 5 minute timestep over a full simulation year.

Macdonald (2009) previously examined sampling techniques for Monte Carlo applications in the context of building performance simulation sensitivity analysis. Using a building natural ventilation problem, they demonstrated that compared to stratified and Latin Hypercube sampling, simple sampling did not produce significantly different results, and that for Monte Carlo uncertainty analyses approximately 100 samples using simple sampling was sufficient for most practical building simulation applications.

The total envelope leakage area was assumed to be equal to $A_{L} @ 4 \mathrm{~Pa}$, provided in Table 1 , since under 
normal operating conditions building envelopes typically experience 0 to $10 \mathrm{~Pa}$ (Sherman and Grimsrud, 1980a). The equivalent or effective envelope leakage has been observed in field studies to vary with magnitude of envelope $\Delta \mathrm{P}$, as well as with whether the building is pressurized or depressurized. This variation is typically attributed to "valving" at some of the leakage sites, especially at higher pressure differentials (Sherman and Chan, 2004). The principle of valving is that leakage sites may close up under higher $\Delta \mathrm{P}$ conditions. Related is the "diode effect" of envelopes, where a leakage site may open up under pressurization but not depressurization, or vice versa. For the purposes of this work $A_{L} @ 4$ Pa was assumed to be a nominal leakage area for the envelope under typical operating conditions.

\section{Results}

\section{Sensitivity to Leakage Distribution with No Pressurization}

Figure 5 plots the distributions of whole-building annual space heating demand and whole-building average annual infiltration rates for the 500 samples under no mechanical pressurization. The mean value of space heating demand is $18.8 \mathrm{MWh}$, with a sample standard deviation of $0.58 \mathrm{MWh}$ (or $3 \%$ of the mean). For average annual infiltration in Figure 5, the mean is $0.038 \mathrm{~kg}_{\text {air }} / \mathrm{s}$ with a sample standard deviation of $0.004 \mathrm{~kg}_{a i r} / \mathrm{s}$ (10\% of the mean). Both demand and infiltration distributions are negatively skewed, with skewness values of -3.7 and -4.5 , respectively.

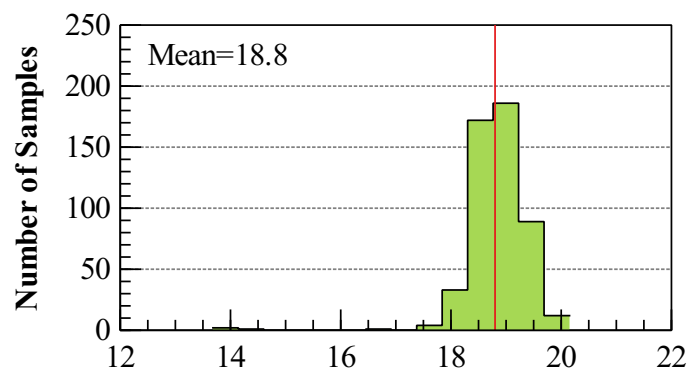

Annual Space Heating Demand [MWh]

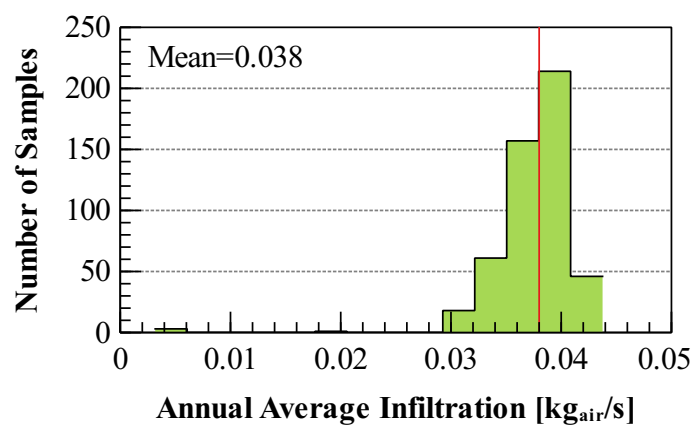

Figure 5: Distributions of annual space heating demand and annual average infiltration under no pressurization.
Specific opening components in the AFN allow for air mixing between the heated zones in the model, shown in Figure 3. This was to account for stairwell and crack openings between the zones, and air mixing by the AHU. Therefore the location the infiltration was entering the envelope did not significantly impact annual energy performance. This can be seen through the strong correlation between average annual infiltration and space heating demand in Figure 6.

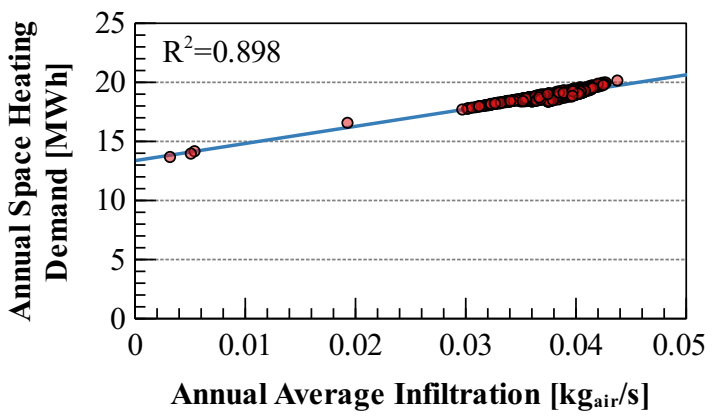

Figure 6: Annual whole-building space heating demand versus average annual infiltration.

The average annual infiltration mass flow rate, however, is dependent on the leakage distribution. To explore the interaction between leakage distribution and infiltration flow rate, the samples corresponding to maximum and minimum annual space heating demand in Figure 6 were examined. The distributions of the leakage area for these samples are provided in Table 4. The annual demands are 20.1 and 13.7 MWh/year, respectively. The average annual infiltration rates are 0.044 and $0.003 \mathrm{~kg}_{\text {air }} / \mathrm{s}$, respectively.

Table 4: Maximum and minimum space heating demand leakage distributions.

\begin{tabular}{|c|c|c|}
\hline \multirow[b]{2}{*}{ Crack Group } & \multicolumn{2}{|c|}{$\begin{array}{l}\text { Fraction of Total } \\
\text { Leakage Area }\end{array}$} \\
\hline & $\begin{array}{l}\text { Max. } \\
\text { Demand }\end{array}$ & $\begin{array}{l}\text { Min. } \\
\text { Demand }\end{array}$ \\
\hline First storey floor & $51.4 \%$ & $0.0 \%$ \\
\hline First storey wall & $0.5 \%$ & $1.7 \%$ \\
\hline First-second interface & $2.3 \%$ & $0.0 \%$ \\
\hline Second storey wall & $0.5 \%$ & $97.8 \%$ \\
\hline Second storey ceiling & $47.3 \%$ & $0.5 \%$ \\
\hline
\end{tabular}

For the maximum annual space heating demand sample, the total envelope leakage area is divided approximately evenly between the first storey floor and second storey leakage. Under this configuration the infiltration stack effect is maximized ${ }^{2}$; the relative elevation between the two leakage sites is the greatest. For the minimum annual space heating demand sample, the total envelope leakage area is concentrated

\footnotetext{
${ }^{2}$ See Equation 23 in ASHRAE (2009)
} 
at a single elevation. Therefore, there is minimal to no stack effect driving infiltration, and infiltration is principally wind-driven.

In practice it is unlikely that all envelope air leakage will be concentrated at a single component or assembly at the same elevation. Therefore, the minimum demand leakage distribution scenario in Table 4 is not likely to occur. The maximum demand scenario, however, is more feasible since it represents leakage at different building envelope component interfaces.

\section{Constant Mass Flow Infiltration}

$\mathrm{Ng}$ et al. (2013) stated that constant infiltration rates neglect the important influences of changing weather conditions. Djunaedy et al. (2003) also noted that the selection of the constant infiltration rate is based on "guessed" values. The detailed AFN simulations conducted in this study have yielded a range of estimates for annual average infiltration rates, which vary based upon leakage location. It was of interest in this work to examine if these annual average infiltration rates could be used as a constant infiltration rate to simplify energy modelling.

The maximum and minimum annual average infiltration rates found in the sensitivity study were considered: 0.044 and $0.003 \mathrm{~kg}_{a i r} / \mathrm{s}$, respectively. Two additional annual simulations of the IARL model were conducted; one with a constant infiltration of 0.044 $\mathrm{kg}_{\text {air }} / \mathrm{s}$, and one with a constant infiltration of 0.003 $\mathrm{kg}_{\text {air }} / \mathrm{s}$. These mass flow rates were divided between the three conditioned zones on a volume-weighted basis.

Table 5: Comparing AFN and constant mass flow annual space heating demand.

\begin{tabular}{l|ll|l}
\hline \hline $\begin{array}{l}\text { Annual } \\
\text { Infiltration } \\
\text { Rate } \\
{\left[\mathbf{k g}_{\text {air }} / \mathrm{s}\right]}\end{array}$ & \multicolumn{2}{|c|}{$\begin{array}{c}\text { Annual Space } \\
\text { Heating } \\
\text { Demand [MWh] }\end{array}$} & $\begin{array}{l}\text { Percent } \\
\text { Difference }\end{array}$ \\
\cline { 2 - 3 } & AFN & $\begin{array}{l}\text { Const. } \\
\text { flow }\end{array}$ & \\
\hline \hline 0.044 & & 19.0 & $6 \%$ \\
0.003 & 13.7 & 14.0 & $2 \%$ \\
\hline \hline
\end{tabular}

The difference in annual space heating demand is between $2 \%$ and $6 \%$, with the difference increasing with infiltration rate, shown in Table 5. The findings here seem to agree with the statement made previously by Djunaedy et al. (2003); that constant flow is sufficient for annual energy estimation. This, however, is only shown for a single building case study, and may not be extended to all buildings, particularly those which are taller, have higher envelope leakage, or buildings with increasingly high thermal resistance.

\section{Variation of Sensitivity with Pressurization}

Figure 7 plots the distributions of annual heating demand under different pressurization scenarios. Building pressurization is created via supply air and is modelled as unconditioned outdoor air entering the basement, shown in Figure 3. The ideal heating controls in the model determine and supply at each simulation timestep the quantity of thermal energy injected at each air node to maintain an indoor temperature of $22{ }^{\circ} \mathrm{C}$. Therefore, the space heating demands will increase with pressurization, shown in Figure 7.

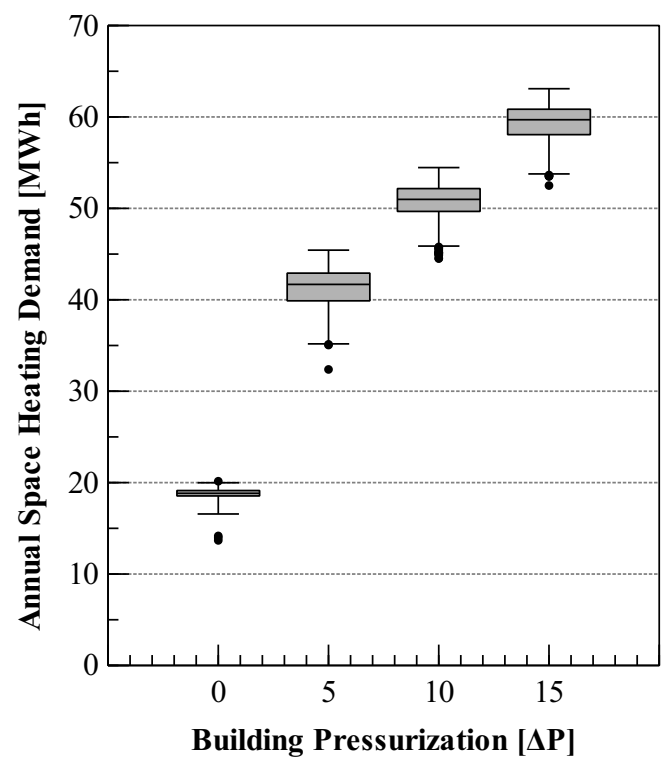

Figure 7: Annual space heating demand variation under pressurization.

The sample standard deviations for each pressurization scenario are provided in Table 6 . The data suggests that there is an increase in leakage distribution sensitivity as the building is pressurized. Using the Brown-Forsythe test ${ }^{3}$, the difference in annual heating demand variation between the pressurization scenarios an no-pressurization is statistically significant $(\alpha=0.05)$.

Table 6: Standard deviation of space heating demand under pressurization scenarios.

\begin{tabular}{ll}
\hline \hline $\begin{array}{l}\text { Induced Pressure } \\
\text { Difference }[\mathbf{P a}]\end{array}$ & $\begin{array}{l}\text { Demand } \\
\text { Deviation }[\mathbf{M W h}]\end{array}$ \\
\hline \hline None & $\begin{array}{l}\text { Standard } \\
{[5}\end{array}$ \\
10 & 1.45 \\
15 & 1.57 \\
\hline \hline
\end{tabular}

\section{Discussion and Conclusions}

The findings in this study do not support the hypothesis that pressurization reduces the sensitivity of

\footnotetext{
${ }^{3}$ The Brown-Forsythe test is used to test the assumption of equal variances between sample groups.
} 
annual building space heating demand to location of envelope air leakage sites. The simulation data presented here shows that the sensitivity, characterized by the standard deviation of the randomly generated samples, increases with pressurization. The difference in this variability of annual energy performance was additionally shown to be significant using a BrownForsythe test $(\alpha=0.05)$. Therefore, the results of this case study suggest that modelling infiltration of pressurized commercial buildings are subjected to similar challenges when characterizing infiltration, especially in regards to envelope leakage site location.

The results also showed that under no pressurization, the variation of envelope air leakage sites caused a $3 \%$ variation in the annual space heating demand estimates. This finding suggests that for a low-rise commercial building with typical to better than typical airtightness $(2.30 \mathrm{ACH} @ \Delta \mathrm{P}=50 \mathrm{~Pa}$ for this case) the location of the envelope leakage sites may be assumed with negligible impact on the estimates. This conclusion, however, may not be extended to taller, higher envelope thermal resistance, and/or leakier buildings which will be the subject of a further study.

Finally, the annual space heating demand estimates produced by the AFN were compared to estimates generated assuming constant mass flow infiltration. The difference in annual energy demand estimates using the maximum and minimum annual average infiltration flow rates from the non-pressurized AFN Monte Carlo study were found to be between $2 \%$ and $6 \%$. Therefore, the case study suggests that for low-rise commercial, assuming a constant infiltration flow rate in simulation models for code-compliance is potentially acceptable. Determining an appropriate value for this flow rate, however, is non-trivial. As suggested in the results of this case study, average infiltration flow rates are strongly determined by leakage site location and distribution which cannot be easily estimated.

\section{Future Work}

This study only examined the variation of stack effect, but did not examine the influence of directional variability of the leakage distribution. Common leakage sites in a building envelope include door and window frames which are not typically distributed evenly on all façades of the building. Future studies will examine how facing direction of leakage sites, considered in the context of dominant wind direction for the location, impact the energy performance of buildings. A fixed whole-building leakage area was also assumed in this case study based on experimental measurements. Future work will also examine how the sensitivity of annual energy performance to leakage distribution varies with total envelope leakage area. The hypothesis of this work is that sensitivity of annual energy performance to leakage distribution diminishes with pressurization of the building.
This study was also limited by a single case study building. To determine more general observations of building performance and envelope leakage distribution, a wider set of built forms need to be considered. Future work will consider buildings of different heights and aspect ratios to discern if the conclusions determined in this work hold true for a variety of built forms.

Finally, the IARL test facility was used as a case study for this research. The facility is equipped with dampers which can vary both the size and location of the envelope leakage area. Future experimental work is planned to verify the simulation conclusions contained within this study.

\section{Acknowledgment}

This study has been carried out with the support of the NRCan's Program of Energy Research and Development (PERD).

\section{References}

ASHRAE (2009). Ventilation and infiltration. In ASHRAE Handbook: Fundamentals, Chapter 16. American Society of Heating, Refrigerating and Air-Conditioning Engineers, Inc. Atlanta (US).

ASHRAE (2011). ANSI/ASHRAE 140 Standard Method of Test for the Evaluation of Building Energy Analysis Computer Programs. American Society of Heating, Refrigerating and Air-Conditioning Engineers, Inc. Atlanta (US).

ASTM (2010). Ery9-10 Standard test method for determining air leakage rate by fan pressurization. American Society for Testing and Materials. West Conshohocken (US).

CCBFC (2015). National Energy Code of Canada for Buildings. Canadian Commission on Building and Fire Codes, Codes Canada, National Research Council of Canada. Ottawa (Canada).

CGSB (1986). CAN/CGSB-149.10-M86 Determination of the airtightness of building envelopes by the fan depressurization method. Canadian General Standards Board. Ottawa (Canada).

Clarke, J. A. (2001). Energy Simulation in Building Design. Butterworth-Heinemann. Oxford (UK).

Clarke, J. A. (2019). ESP-r. Available online at https://www.strath.ac.uk/research/ energysystemsresearchunit/applications/esp-r/. [Accessed: 2019-01-15].

Deru, M., K. Field, D. Studer, K. Benne, B. Griffith, P. Torcellini, B. Liu, M. Halverson, D. Winiarski, M. Rosenberg, M. Yazdanian, J. Huang, and D. Crawley (2011). U.S. Department of Energy Commercial Reference Building Models of the $\mathrm{Na}$ tional Building Stock. National Renewable Energy 
Laboratory, U.S. Department of Energy. Golden (US).

Djunaedy, E., J. L. M. Hensen, and M. G. L. C. Loomans (2003). Development of a guideline for selecting a simulation tool for airflow prediction. In Proceedings from the Eighth International IBPSA Conference. Eindhoven (NL), 11-14 August 2003.

ECCC (2018). Engineering climate datasets. Available online at http://climate.weather.gc.ca/prods_ servs/engineering_e.html. [Accessed: 2018-05-31].

Girgis, E. (2012). Building energy performance compliance path: NECB Part 8. Available online at https://www.nrc-cnrc.gc.ca/eng/ solutions/advisory/codes_centre/presentations/ 2011/compliance.html. [Accessed: 2019-02-08].

Gowri, K., D. Winiarski, and R. Jarnagin (2009). Infiltration Modeling Guidelines for Commercial Building Energy Analysis. Pacifc Northwest National Laboratory. Richland (US).

Hensen, J. (1991). On the Thermal Interaction of Biuilding Structure and Heating and Ventilating System. Ph.D. thesis. Technische Universiteit Eindhoven. Eindhoven (NL).

Judkoff, R. and J. Neymark (1995). International Energy Agency Building Energy Simulation Test (BESTEST) and Diagnostic Method. National Renewable Energy Laboratory. Golden (US).

Liddament, M. W. (1986). Air Infiltration Calculation Techniques - An Applications Guide. The Air Infiltration and Ventilation Centre, University of Warwick Science Park. Coventry (UK).

Lstiburek, J. and J. Carmody (1994). Moisture control handbook: principles and practices for residential and small commercial buildings. John Wiley \& Sons. New York (US).

Macdonald, I. (2009). Comparison of sampling techniques on the performance of Monte-Carlo based sensitivity analysis. In Proceedings from the Eleventh International IBPSA Conference. Glasgow (UK), 27-30 July 2009.

Ng, L. C., A. Musser, A. K. Persily, and S. J. Emmerich (2013). Multizone airflow models for calculating infiltration rates in commercial reference buildings. Energy and Buildings 58, 11-18.

Province of British Columbia (2017). Energy step code building beyond the standard. Available online at www.energystepcode.ca/. [Accessed: 201901-15].

Shaw, C. Y. and G. T. Tamura (1977). The calculation of air infiltration rates caused by wind and stack action for tall buildings. ASHRAE Transactions 83(2), 145-158.
Sherman, M. H. and W. R. Chan (2004). Building air tightness: research and practice. Lawrence Berkeley Laboratory, University of California. Berkeley (US).

Sherman, M. H. and D. T. Grimsrud (1980a). Infiltration-Pressurization Correlation: Simplified Physical Modelling. Lawrence Berkeley Laboratory, University of California. Berkeley (US).

Sherman, M. H. and D. T. Grimsrud (1980b). Measurement of infiltration using fan pressurization and weather data. In Proceedings from the First Symposium of the Air Infiltration Centre on Instrumentation and Measurements Techniques. Windsor (UK), 6-8 October 1980.

Strachan, P., G. Kokogiannakis, and I. A. Macdonald (2008). History and development of validation with the esp-r simulation program. Building and Environment 43(4), 601-609.

Walker, I. and D. Wilson (1990). The Alberta Air Infiltration Model: AIM-2. University of Alberta, Department of Mechanical Engineering. Edmonton (Canada). 